\title{
Tempering of Martensitic Stainless Steel with 0.6 w/o Nitogen and /or Carbon
}

\author{
H. Berns and V. Gavriljuk* \\ Ruhr-Universität Bochum, Institute for Materials, Universitätsstr. 150, 44780 Bochum, Germany \\ * Institute of Metal Physics, 35 acad. Vernadsky Blvd, 252142 Kiev, Ukraine
}

\begin{abstract}
Martensitic stainless high nitrogen steels are used for advanced bearings because of their superior corrosion resistance and hot hardness. Therefore the tempering behaviour of steels SC, SN and SNC with close to $15 \mathrm{w} / \mathrm{o} \mathrm{Cr}, 1 \mathrm{w} / \mathrm{o}$ Mo and $0.6 \mathrm{w} / \mathrm{o} \mathrm{C}, \mathrm{N}$ or $\mathrm{C}+\mathrm{N}$, respectively, was investigated. Secondary hardening is enhanced by nitrogen, which also increase the content of retained austenite and its resistance to tempering especially in SNC. During tempering $\epsilon_{-}, \theta$ - and $M_{7} C_{3}$-carbides precipitate in SC while $\epsilon-, \zeta-$ and $M_{2} N$-nitrides appear in SN. In SNC carbides and nitrides precipitate separately. Mössbauer spectroskopy revealed clustering of solute atoms in SC and ordering in SN and more so in SNC.
\end{abstract}

\section{INTRODUCTION}

It is well known that dissolved nitrogen enhances the corrosion resistance of stainless steel. By proper alloying as well as by pressure or powder metallurgy the content of this volatile element may be increased above $0.3 \mathrm{w} / \mathrm{o}$. These high nitrogen steels (HNS) are a new class of materials used for high strength parts in a corrosive environment [1]. A martensitic type of HNS was developed for stainless tools and bearings [2]. Today, HNS ball screws are used to operate flap traps of aircraft and fuel pumps of the space shuttle are equipped with HNS bearings.

It was found that nitrogen eases the dissolution of precipitates during austenitizing of a martensitic steel with $15 \mathrm{w} / \mathrm{o} . \mathrm{Cr}$ and $1 \mathrm{w} / \mathrm{o}$ Mo resulting in a higher content of retained austenite as compared to carbon. Upon tempering secondary hardening at about $450^{\circ} \mathrm{C}$ is more pronounced in HNS than in carbon grades. In addition, the corrosion resistance is hardly effected in HNS after tempering at this temperature while respective carbon grades loose most of their passivation. To understand the different tempering behaviour of stainless martensitic steels containing $\mathrm{C}, \mathrm{N}$ or $\mathrm{C}+\mathrm{N}$ an extensive study on the precipitation sequence and the atomic order of solute atoms in the matrix was performed.

\section{EXPERIMENTAL}

Three steels with close to $15 \mathrm{w} / \mathrm{o} \mathrm{Cr}$ and $1 \mathrm{w} / \mathrm{o}$ Mo were prepared. Steel SC contained $0.6 \mathrm{w} / \mathrm{o} \mathrm{C}$ and was manufactured by vacuum induction melting. Steel SN was alloyed with $0.62 \mathrm{w} / \mathrm{o} \mathrm{N}$ and produced by powder metallurgy, i.e. hot isostatic pressing of nitrided steel powder. Pressurizedelectro-slag-remelting (PESR) was employed to give steel SNC with $0.35 \mathrm{w} / \mathrm{o} \mathrm{N}$ and $0.29 \mathrm{w} / \mathrm{o} \mathrm{C}$. The steels were forged to rods, soft annealed, austenitized at $1100^{\circ} \mathrm{C}$ for 30 minutes and quenched in water. Some specimens were deep freezed in liquid nitrogen $\left(-196^{\circ} \mathrm{C}\right)$ immediately afterwards. Tempering was carried out at temperatures between 200 and $650{ }^{\circ} \mathrm{C}$ for two hours.

The Vickers hardness was taken in the as-quenched and tempered states. Internal friction measurements were performed at a frequency of 0.4 to $5.5 \mathrm{~Hz}$ using a fully automated inverted torsion pendulum. The strain amplitude was about $10^{-5}$. A magnetic field of about $0.09 \mathrm{~T}$ was applied to avoid a possible contribution of magnetic damping. The size change during tempering was recorded in forging direction using an inductive dilatometer operating in vacuum. Mössbauer 
studies were carried out to get information on the content of retained austenite and the order of $\mathrm{Cr}$ atoms. ${ }^{57} \mathrm{Co}$ in a $\mathrm{Cr}$ matrix with an activity of about $25 \mathrm{mC}$ was used as a source of $\gamma$-quanta. The velocity scan non-linearity was less than $0.45 \%$ at the measurement conditions used. The spectra were fitted using a Lorenz shape of lines, the line width being considered as an iteration parameter which accounted for a finite thickness of the absorber as well as for unresolved effects of solute atoms which are located outside of the two coordination shells around an iron atom in the origin. Transmission electron microscopy (TEM) was performed at a voltage of $200 \mathrm{kV}$ using a STEM-unit for obtaining microdiffraction patterns of extremely small areas $20 \mathrm{~nm}$ in diameter. Diffraction patterns of areas $0.5 \mu \mathrm{m}$ in diameter were obtained by conventional selected area diffraction (SAD) technique. The patterns were evaluated by means of a computer programme. An energy dispersive $\mathrm{X}$-ray-detector (EDX) equipped with an ultrathin window was used to analyze the fine precipitates. The STEM technique provided a spacial resolution of analyses of about $20 \mathrm{~nm}$.

\section{RESULTS AND DISCUSSION}

The distribution of solute atoms in the austenite is inherited by the martensite and affects the tempering behaviour.

\subsection{As quenched state}

Undissolved coarse $\mathrm{M}_{23} \mathrm{C}_{6}$ carbides are encountered in SC and respective $\mathrm{M}_{3} \mathrm{C}$ particles in SNC material. SN was free of coarse precipitates. The content of retained austenite (RA) increased in the order of SC, SN, SNC (Table 1) indicating a higher stability of the austenite to martensitic transformation. Short range atomic ordering of solute atoms due to nitrogen is considered to be the cause of this behaviour [3]. In binary iron alloys ordering of $\mathrm{N}$-atoms was reported [4] while clustering of $\mathrm{C}$-atoms was observed in $\mathrm{FeNiC}$ and $\mathrm{FeMnC}$ austenites [5,6]. Strengthening of the covalent interatomic bond in $\mathrm{Fe}$-Cr-alloys occurs due to $\mathrm{Cr}$ because of spending free electrons for filling the holes created by $\mathrm{Cr}$ in the d-band, which favours $\mathrm{CrCr}$-pairs instead of $\mathrm{FeCr}$-pairs, thus promoting clustering of $\mathrm{Cr}$-atoms. Therefore clustering is to be expected in $\mathrm{FeCrC}$-alloys, too. Nitrogen, however, seems to entail a more homogeneous ordered distribution of Cr-atoms in iron. Due to the rising content of RA the hardness decreases in the order of SC, SN, SNC. In all three alloys the martensite consists of dislocated and twinned areas.

\subsection{Precipitates in tempered martensite}

TEM and dilatometric studies revealed the following precipitation sequences in the tempering range of 200 to $650^{\circ} \mathrm{C}[7,8]$ :

$$
\begin{gathered}
\mathrm{SC}: \epsilon-(\mathrm{Fe}, \mathrm{Cr})_{2} \mathrm{C}(\text { hex }) \rightarrow \Theta-(\mathrm{Fe}, \mathrm{Cr})_{3} \mathrm{C}(\text { orh }) \rightarrow(\mathrm{CrFe})_{7} \mathrm{C}_{3}(\text { hex }) \\
\mathrm{SN}: \epsilon-(\mathrm{Fe}, \mathrm{Cr})_{2} \mathrm{~N}(\mathrm{hex}) \rightarrow \zeta-(\mathrm{Fe}, \mathrm{Cr})_{2} \mathrm{~N}(\text { orh }) \rightarrow(\mathrm{CrFe})_{2} \mathrm{~N}(\text { hex }) \\
\mathrm{SNC}: \epsilon-(\mathrm{Fe}, \mathrm{Cr})_{2} \mathrm{C}(\mathrm{hex}) \rightarrow \Theta-(\mathrm{Fe}, \mathrm{Cr})_{3} \mathrm{C}(\mathrm{orh}) \\
\epsilon-(\mathrm{Fe}, \mathrm{Cr})_{2} \mathrm{~N}(\text { hex }) \rightarrow(\mathrm{Cr}, \mathrm{Fe}) \mathrm{N}(\mathrm{fcc}) \rightarrow(\mathrm{Cr}, \mathrm{Fe})_{2} \mathrm{~N}(\text { hex })
\end{gathered}
$$

The formation of readily coarsening cementite in SC and SNC at $\sim 300^{\circ} \mathrm{C}$ is accompanied by a drop in hardness (Fig. 1), while secondary hardening at $\sim 450^{\circ} \mathrm{C}$ is promoted by different precipitates. In $\mathrm{SC}$ the $\mathrm{M}_{7} \mathrm{C}_{3}$ carbides are most likely not precipitated in-situ, which shifts their formation to a slightly higher temperature and enhances overaging. In contrast, the in-situ precipitation of $\zeta$ particles promotes secondary hardening in $\mathrm{SN}$. While $\mathrm{M}_{7} \mathrm{C}_{3}$ is enriched in $\mathrm{Cr}$ the $\zeta$-phase contains about as much as the matrix. This is supposed to be the reason for the higher corrosion resistance of $\mathrm{SN}$ as compared to $\mathrm{SC}$ after tempering in the secondary hardening regime. In low tempered SNC iron carbides and nitrides form separately, although $\mathrm{Fe}_{2,3}(\mathrm{C}, \mathrm{N})$ carbonitides have been reported, too [9]. Secondary hardening is brought about by $(\mathrm{Cr}, \mathrm{Fe}) \mathrm{N}$ which was not detected in SN. The 
equilibrium phases after tempering at $650^{\circ} \mathrm{C}$ are $\mathrm{M}_{7} \mathrm{C}_{3}$ in $\mathrm{SC}, \mathrm{M}_{2} \mathrm{~N}$ in $\mathrm{SN}$ and $\mathrm{M}_{3} \mathrm{C}$ as well as $\mathrm{M}_{2} \mathrm{~N}$ in SNC. In the latter material $\mathrm{M}_{3} \mathrm{C}$ instead of $\mathrm{M}_{7} \mathrm{C}_{3}$ is unexpected. EDX analyses showed that this cementite contains $\sim 53 \mathrm{w} / \mathrm{o} \mathrm{Cr}$ while the coarse undissolved cementite particles have picked up only $\sim 16 \mathrm{w} / \mathrm{o} \mathrm{Cr}$. According to e.g. [10] the $\mathrm{Cr}$ content of cementite does not exceed $\sim 20 \mathrm{w} / \mathrm{o}$, although an enrichment was observed before the formation of $\mathrm{M}_{7} \mathrm{C}_{3}$ [11]. It is supposed that at a lower tempering temperature (e.g. $\sim 450{ }^{\circ} \mathrm{C}$ ) $\mathrm{M}_{3} \mathrm{C}$ and $\mathrm{MN}$ contain about as much $\mathrm{Cr}$ as the Matrix. A migration of $\mathrm{Cr}$ atoms from the matrix into the precipitates will occur due to the higher affinity of $\mathrm{Cr}$ to the interstitials as compared to $\mathrm{Fe}$. In a competition between carbon and nitrogen in their affinity to $\mathrm{Cr}$ the $\mathrm{M}_{2} \mathrm{~N}$ reaches a $\mathrm{Cr}$ content of $\sim 58 \mathrm{w} / \mathrm{o}$ at $650^{\circ} \mathrm{C}$ which is above that of cementite. The transformation from $\mathrm{MN}$ to $\mathrm{M}_{2} \mathrm{~N}$ maybe governing this competition hindering the formation of $\mathrm{M}_{7} \mathrm{C}_{3}$.

Comparing the microstructure of $\mathrm{SC}$ and $\mathrm{SN}$ after tempering at $650{ }^{\circ} \mathrm{C}$ the nitrides are considerably smaller and more evenly dispersed in the matrix. This is consistent with observations made on quenched and tempered HNS and creep resistant HNS [12, 13].

\subsection{Tempering effects in the matrix}

The stability of RA to tempering increases in the order of SC, SN, SNC (Table 1). The high content of RA after tempering SNC at $600{ }^{\circ} \mathrm{C}$ was unexpected. Therefore Mössbauer spectroscopy was applied to investigate the order of $\mathrm{Cr}$ atoms in martensite tempered at $650^{\circ} \mathrm{C}$ and depleted of dissolved interstitial atoms [3]. The hyperfine magnetic field of an iron atom is changed by a fixed amount if a $\mathrm{Cr}$ atom is dissolved in the first and second coordination sphere. The evaluation of Mössbauer data allows to define the abundances of iron atoms with 0 to $5 \mathrm{Cr}$ atoms as nearest neighbours, i.e. $\mathrm{Fe}_{0}$ to $\mathrm{Fe}_{5}$. The results are given in Table 2 omitting $\mathrm{Fe}_{4}$ and $\mathrm{Fe}_{5}$ because of a lack in accuracy. An increase of $\mathrm{Fe}_{1}$ and $\mathrm{Fe}_{2}$ as well as a decrease of $\mathrm{Fe}_{0}$ and $\mathrm{Fe}_{3}$ occurs in the order of $\mathrm{SC}, \mathrm{SN}, \mathrm{SNC}$ and points to a more homogeneous distribution of $\mathrm{Cr}$ atoms, i.e. to short range atomic ordering (Fig. 2). The Cowley parameter $\alpha_{1}$ describes the deviation from a statistical distribution of solute atoms and becomes negative for ordering and positive for clustering [14]. The values derived from the experimental abundances of $\mathrm{Fe}_{0}$ sites amount to $\alpha_{1}(\mathrm{SC})=0.17, \alpha_{1}(\mathrm{SN})=-0.02, \alpha_{1}$ $(\mathrm{SNC})=-0.2[8]$. It is most likely that the state of atomic order was inherited from the parent austenite and is still pertaining after tempering. The reason for the high degree of ordering in SNC is not clear. One can suppose that the separate precipitation of carbides and nitrides needs a redistribution of $\mathrm{C}$ - and $\mathrm{N}$-interstitials as a preliminary stage, which results in a delay of $\mathrm{Cr}$-redistribution. Ordering of solute atoms increases the stability of austenite to transformation and promotes a fine distribution of precipitates.

The change of internal friction $\left(\mathrm{Q}^{-1}\right)$ and frequency (shear modulus $\mathrm{f}^{2}$ ) during tempering of an SC and SN martensite shows a peak of damping centered at 250 to $280^{\circ} \mathrm{C}$ which is accompanied by a modulus effect and therefore assigned to a Snoek-Köster (S-K) relaxation caused by a movement of dislocations dragging interstitial atoms $[15,16]$. The activation enthalpy of the peak $(\mathbf{H}=$ $1,35 \mathrm{eV})$ and the preexponential factor $\left(\tau_{0}=4,6 \times 10^{15} \mathrm{~s}\right)$ which were determined by measuring at different frequencies are typical values of S-K-relaxation. The mechanism of this phenomenon is not yet unambiguously explained $[17,18]$. However, as a first approximation the intensity of relaxation can be considered proportional to an area swept by dislocations with dragged solutes. The intensity of relaxation for the nitrogen martensite is three times as large as that for the carbon one at a similar concentration of interstitials. Such a difference is consistent with a preferential contribution of nitrogen atoms to the S-K-relaxation which is generally observed $[17,18]$. The results obtained point to a higher mobility of dislocations in nitrogen martensite tempered in the range of the S-Kpeak. After heating SN to $650^{\circ} \mathrm{C}$ the decomposition of RA is shown in the cooling curve which is consistent with dilatometric data. 
RA is quite stable in SNC up to $600^{\circ} \mathrm{C}$. A significant splitting of dislocations is observed by TEM after tempering at $550^{\circ} \mathrm{C}$. The segregation of interstitial atoms may be responsible for the decrease of stacking fault energy.

\section{CONCLUSIONS}

The following conclusions are derived from experimental results on quenched and tempered stainless martensitic steels containing about $0.6 \mathrm{w} / \mathrm{o}$ of $\mathrm{C}$ (steel SC), of $\mathrm{N}$ (steel SN) or of C $+\mathrm{N}$ (steel SNC).

(a)After quenching from $1100^{\circ} \mathrm{C}$ the content of retained austenite increases in the order of SC, SN, SNC.

(b)The transformation of retained austenite during tempering is retarded in the same order.

(c)After tempering at $650^{\circ} \mathrm{C}$ Mössbauer spectra indicate clustering of solute atoms in SC and short range atomic ordering in $\mathrm{SN}$ and more so in $\mathrm{SNC}$.

(d)It is supposed that the stated of atomic order in the martensite is inherited from the parent austenite, which becomes more resistant to martensitic transformation as ordering is enhanced.

(e)The precipitation sequence during tempering from 200 to $650^{\circ} \mathrm{C}$ is $\epsilon$-carbide, cementite and $\mathrm{M}_{7} \mathrm{C}_{3}$ for SC but $\epsilon$-nitride, $\zeta$-nitride and $\mathrm{M}_{2} \mathrm{~N}$ for $\mathrm{SN}$. The lower $\mathrm{Cr}$-content and finer distribution of the $\zeta$-nitrides as compared to the $\mathrm{M}_{7} \mathrm{C}_{3}$-carbides seems to be responsible for the higher corrosion resistance and hardness after tempering in the regime of secondary hardening at $\sim 450{ }^{\circ} \mathrm{C}$.

(f)No carbonitrides are detected in SNC after tempering. Instead carbides and nitrides form separately. Cementite is enriched in $\mathrm{Cr}$ but does not transform to $\mathrm{M}_{7} \mathrm{C}_{3}$. Cubic $\mathrm{MN}$ appears as an intermediate phase in the regime of secondary hardening which is not observed in $\mathrm{SN}$.

\section{References}

[1] Berns H., Z.Metallkd. 86 (1995) 3, 156-163

[2] Berns H., Ehrhardt R. and Siebert S., Mat.-wiss. u. Werkstofftech. 27 (1996) 25-36

[3] Berns H., Ehrhardt R, Duz V.A. and Gavriljuk V.G., Met.Phys.Adv.Tech. 15 (1995) 561-570

[4] Foct J., C.R.Acad. Sci.Paris 276 (1973) 1159-1162

[5] Bugaev V.N., Gavriljuk V.G., Nadutov V.M. and Tatarenko V.A., Acta Metall. 31 (1983) 3, 407-418

[6] Bugaev V.N., Gavriljuk V.G., Nadutov V.M. and Tatarenko V.A., Reports of Academy of Sci. of USSR 288 (1986) 2, 362-366

[7] Berns H., Bugajchuk S.N., Duz V.A., Ehrhardt R., Gavriljuk V.G., Petrov Y.N. and Yakubzov I.A., steel res. 65 (1994) 10, 444-450

[8] Berns H., Duz V.A., Ehrhardt E., Gavriljuk V.G., Petrov Yu N. and Tarasenko A.V., Z.Metallkd. 88 (1997) 2

[9] Pearsons W.B., in: A Handbook of Lattice Spacings and Structures of Metals and Alloys, G.V. Rainor (ed.), Pergamon Press, NY, 4 (1964) 924

[10] Bungardt K., Kunze E. and Horn E., Arch.Eisenhüttenw. 29 (1958) 1-11

[11] Gridnev V.N., Gavriljuk V.G., Nadutov V.M., Phys.Met.Metallogr. 60 (1985) 590-598

[12] Berns H. and Ehrhardt R., steel res. 67 (1996) 8, 343-349

[13] Berns H., Krafft F., "12\% Chromium Steels alloyed with Nitrogen under Pressure and the Influence of a TMT on their Mechanical Properties", Conf. Rupture Ductility of Creep Resistant Steels, York, England, Nov. 1990

[14] Cowley J.M., J.Appl.Phys. 21 (1950) 24

[15] Mura T., Tamura I. and Brittain J.D., J.Appl.Phys. 32 (1961) 1, 92-96

[16] Sarrak V.I. and Suvorova S.O., Reports of Academy of Sci. of USSR 208 (1973) 2, 338-341

[17] Köster W., Kampschulte K, Arch. Eisenhüttenw. 32 (1961) 12, 808-828

[18] Gavriljuk V.G., Yagodsinsky Yu.N., Phys.Met.Metallogr. 62 (1986) 2, 253-265 
Table 1: $\quad$ Content of retained austenite (v/o)

\begin{tabular}{||c|c|c|c|c|c|c||}
\hline \multirow{2}{*}{ Steel } & \multicolumn{2}{|c|}{ quenched to } & \multicolumn{4}{c||}{ tempered at } \\
\cline { 2 - 7 } & $20{ }^{\circ} \mathrm{C}$ & $-196{ }^{\circ} \mathrm{C}$ & $400{ }^{\circ} \mathrm{C}$ & $550{ }^{\circ} \mathrm{C}$ & $600{ }^{\circ} \mathrm{C}$ & $650{ }^{\circ} \mathrm{C}$ \\
\hline SC & 24.6 & 7.7 & 0 & 0 & 0 \\
\hline SN & 51.1 & 35.7 & 10.0 & 0 & 0 \\
\hline SNC & 70.9 & 70.9 & 58.1 & 50.5 & 1.8 \\
\hline SNC & \multicolumn{2}{|c|}{31.2} & 31.2 & 28.8 & 0.82 & 0.66 \\
\hline
\end{tabular}

Table 2: $\quad$ Abundances of the iron sites having zero to three chromium atoms, respectively, as nearest neighbours in the first two coordination spheres after tempering at $650^{\circ} \mathrm{C}$

\begin{tabular}{||c|c|c|c|c||}
\hline \multirow{2}{*}{ Steel } & \multicolumn{4}{|c|}{ Abundances, \% } \\
\cline { 2 - 5 } & $\mathrm{Fe}_{0}$ & $\mathrm{Fe}_{1}$ & $\mathrm{Fe}_{2}$ & $\mathrm{Fe}_{3}$ \\
\hline SC & 16.3 & 32.8 & 38.9 & 12.0 \\
\hline SN & 9.9 & 37.3 & 37.3 & 15.3 \\
\hline SNC & 7.7 & 40.9 & 40.6 & 10.7 \\
\hline
\end{tabular}

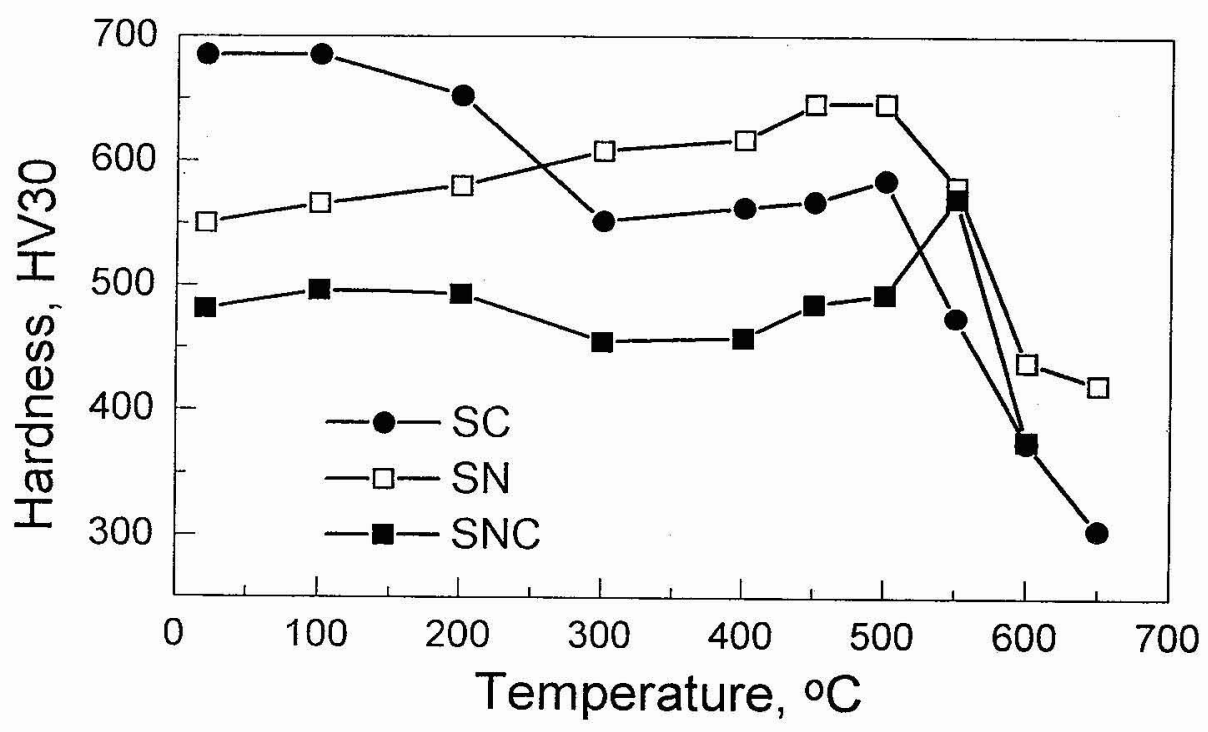

Fig. 1: Hardness after quenching from $1100^{\circ} \mathrm{C}$ and after tempering 

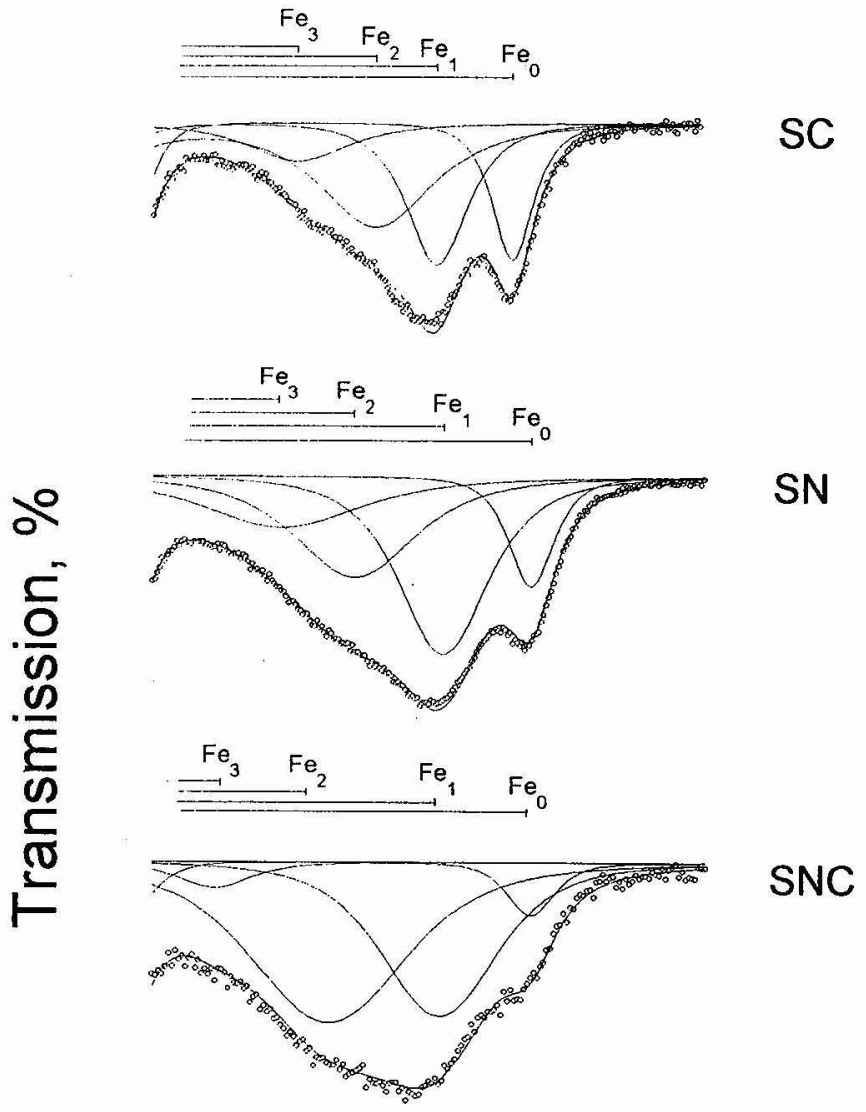

Velocity, $\mathrm{mm} / \mathrm{s}$

Fig. 2: Mössbauer spectra of the steels investigated after tempering at $650^{\circ} \mathrm{C}$ 